\title{
Cities as Novel Biomes: Recognizing Urban Ecosystem Services as Anthropogenic
}

\author{
Stephanie Pincetl * \\ California Center for Sustainable Communities, Institute of the Environment and Sustainability, University of California, \\ Los Angeles, Los Angeles, CA, USA
}

Urban Ecosystem Science is now an established science, arising along side the historic shift of humans to becoming in majority urban dwellers. In this Perspective I suggest there is a need to develop a new framework for UES as embedded in distinct urban biomes that can be classified by city-type and typologized. UES are largely the artifact of human decision making from what to plant where, to determining the urban infrastructure type in which UES will be placed. Developing urban typologies by climate zone, level of development, size and history will better enable the understanding of UES. I attempt to show the rise of the importance of nature, and of urban nature following the development of industrial city, and the importance of human intent in creating these urban ecosystems

OPEN ACCESS

Edited by:

Dagmar Haase,

Humboldt Universität zu Berlin,

Germany

Reviewed by:

Frederick R. Adler,

The University of Utah, USA

Francisco J. Escobedo,

University of Florida, USA

*Correspondence:

Stephanie Pincet/

spincet/@ioes.ucla.edu

Specialty section:

This article was submitted to Urban Ecology,

a section of the journal

Frontiers in Ecology and Evolution

Received: 28 April 2015 Accepted: 26 November 2015 Published: 21 December 2015

Citation:

Pincetl S (2015) Cities as Novel

Biomes: Recognizing Urban

Ecosystem Services as

Anthropogenic.

Front. Ecol. Evol. 3:140.

doi: 10.3389/fevo.2015.00140 over time. If humans choose to manage cities through increasing UES, this will require coupled shifts, the shift in rules and regulations, goals and processes and shifts in urban form, infrastructure and function - socio-technical-ecological changes - driven by human decision-making. Such efforts will vary widely by city - by urban biome.

Keywords: coupled socio-ecological studies, anthropogenic impacts, novel biomes, urban history, ideas of nature

It is fair to say that there have been several thousand papers reporting on urban ecological investigations and numerous reviews of those papers from different perspectives and different continents, with $\mathrm{Wu}$ (2014), Tanner et al. (2014), Haase et al. (2014), being among the most recent. Urban ecological research has emerged as a dynamic field of investigation that mirrors the shift of humans to cities and the growing understanding of cities as hugely important in global biogeochemical changes. One of the driving questions for this research is how urban ecology can make cities more livable and sustainable (Tanner et al., 2014), and the underlying bedrock of this question is the importance of ecosystem services (ES) for humans, built on the Millennium Assessment Report (MEA). Regulating services seem to be the most prevalent in the ES urban ecology literature, along with cultural services, with some studies covering more than one dimension of ES-or more precisely Urban Ecosystem Services-UES (Summers et al., 2012).

In this Perspective I wish to raise several questions about the rise of UES from the lens of a social scientist trained in urban planning and cultural anthropology who has engaged in nearly 20 years of interdisciplinary research with urban ecologists. My intent is to attempt to emphasize that UES are essentially human creations-that it is, artifacts of human intention-and thus that UES must reflect and engage with human decision-making, history, urban and economic growth, and ultimately, unintended consequences more deeply. In so doing, I recognize the pioneering work that has been done by the Baltimore and Phoenix LTER, and leaders in the field who have been pushing for new science and synthesis (Grimm et al., 2000; Pickett et al., 2011). Yet, I suggest we need to go further and develop a new framework for UES-the living elements of 
urban infrastructure-altogether. We need to develop an understanding of UES as embedded in distinct urban biomes that can be classified by city-type and typologized. The typologies would necessarily include not only climate zone, but level of economic development, city size, the history of the transformation of the landscape, urban infrastructure development, and the history of urban vegetation. I will touch on the following to construct this framework, and hope it will contribute to reconceptualizing how MEA principles and intent can be applied to urban areas.

- The shock of the Industrial city

- From nature to UES?

- The historical lineage of attempts to improve cities from the Garden City of Howard (1902) to today's efforts at urban greening-what is new? Does it make a difference?

- Cities as anthropogenic environments-they are biomes

- The role of hard and soft infrastructures

- Toward Studying Urban Biomes

\section{THE SHOCK OF THE INDUSTRIAL CITY}

The industrial revolution enabled the urban concentration of populations at an unprecedented pace and scale. Insalubrious living and working conditions, inhumanely long work days, polluted air and water, crowded conditions, all contributed to the notion that urban dwellers ought to have access to nature to renew their lungs and spirits (Rosenzweig, 1983). It is really only with industrial capitalism's ability to generate economic growth at a pace never experienced before in the world (McNeill, 2001), built on the harnessing of fossil fuels, that the urban revolution and the acceleration of population growth were possible. Industrialization and urbanization coupled with capitalism and population growth, transformed the world. This revolution made the planet urban in a short 250-300 years. With it came a profound change in the ability of humans to impact the globe and human's relationship to nature. The coming together of industrialization built on fossil fuels, capitalism, population growth and scientific advances have made humans the agents of biogeochemical planetary change: humans are a force of nature and responsible for the fate of the globe.

A quick historical retrospective shows the power of the idea of nature. Frederick Law Olmsted's argument for Central Park rested in part on the alleged need of industrial workers to have a natural place to go on Sundays to rest and recuperate. But even before this early urban park link to human health, one can turn to the Romantic Movement to discern a clear line of belief in the importance of nature, and access to nature, for human wellbeing. This would include in the U.S. the Transcendental Movement, the British Romantics such as Blake, Wordsworth, Byron and others in Germany and France (Thacker, 1983) who were the precursors of nature preservation. We therefore see a parallel sentiment-preserve nature out there from depredation, create natural places in cities for human spiritual and physical recovery.
As Denis Cosgrove, a cultural geographer who has written extensively about concepts of landscape and representation, noted, medieval cities contained little to no nature, and instead the Classical hierarchy was city, countryside and wilderness, with clear demarcations between them. With industrial society, most markedly in the nineteenth century, the countryside became urbanized and the "city progressively took upon itself the role traditionally confined to the country or middle landscape, that of actively transforming nature into culture" (Cosgrove, 1993a, p. 49)-hence cultural services, presaging the MEA "cultural services" category. This included the development of Garden Cities advocated for by Howard (1902) where each dwelling unit would have access to gardening and outdoor space, and Geddes' urban planning schemes proposing new towns surrounded by fields and open spaces (Geddes, 1950).

Again, as Cosgrove explains, the nineteenth century was the era of the greening of the city, a phenomenon occurring to counteract the overcrowded, polluted, tenement ridden city Cosgrove (1993b). Much has been written about these tensions and trends (Marx, 1964; Glacken, 1967; Williams, 1973; McHarg, 1992; Luccarelli, 1995; Creese, 1996; Parsons and Schuyler, 2002) that emerge as socio-political reform agendas, based in a belief in the importance of access to nature and open space. And they continue into the twentieth century with the further building of garden cities (even today's suburbs-perhaps the most predominant manifestation of a desire to be surrounded by nature while still being in the city), the struggles to build more urban parks, the federal (in the U.S.) investments in National Recreation Areas, and many other examples beyond the scope of this article (Whyte, 1970; Jackson, 1994; Rome, 2001; Seller, 2012).

The point is to draw attention to a historic interest in, and advocacy for, nature in cities-and/or its preservation on the urban fringe-that largely results from an enormous transformation of human's relationship to nature as a consequence of industrial urbanization. It is this historical lineage that logically takes us to UES-currently a scientized approach to examining nature in the city, and advocating for its utility by quantifying it. UES provides metrics, numbers about nature in the city-quantifies its activities-to show its importance for humans. Frederick Law Olmsted and the Romantics, believed having access to what is not the product of economic activity, was important for human sanity. The paradox, of course, is that today there is a trend toward economizing the UES - the worth of a tree or of honey bees - that a number of scientists feel provides legitimacy for the creation and maintenance of UES (Costanza et al., 2014; Naeem et al., 2015 and much of the iTree calculations, as a clear example of this way of thinking; Figure 1). Such a strategy is the topic of a great deal of debate, but is not the main topic of this discussion. I mention the economic turn because it features often in the efforts to justify certain UES, and that the term nature seems weak in current policy discourse though the idea of nature has been central to the evolution of conservation and the making of urban natural areas.

Though it is clear that a yearning for nature-an amorphous term-emerged as a reaction to industrialization, Williams presciently wrote about the symbolism and multiple meanings 


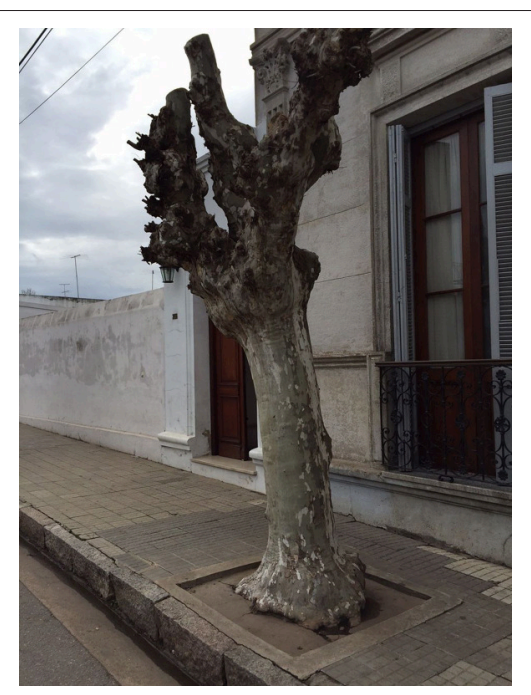

FIGURE 1 | Tree management.

of the word nature Williams (1980). It is a word that ultimately expresses, as Williams writes. how "[W]e have mixed our labor with the earth, our forces with its forces too deeply to be able to draw back and separate either out" (p. 83). Herein is climate change. UES does not sufficiently capture the extraordinary shift in the joining up of humans and the physical world and the complexity of our relationships with the physical world. The city is the most extreme expression of how the whole complex of social and natural relationships are at once our product and our activity (Williams, ibid). UES are inescabably a human creation, yet naturalized.

Such an enormous shift in human impacts on the planet raises the need for more reflexivity in UES, an understanding of how, today, more than ever, the physical environment is deeply affected by human activity, indeed often produced by it. Even in the creation of preserved spaces, humans choose where they are and how they are managed. The continuum's end is the city and UES. Providing more scientific evidence of the importance of ES in cities to human well-being-so called cultural services in the MEA-and to environmental quality-infiltrating water, cooling the atmosphere, hosting pollinators etc.-with little contextualizing of such "services" as the outcomes of choices and urban historical development may have reached the limit of its effectiveness-it is thin philosophically and emotionally. Is urban greening, using the precepts of the MEA, perhaps more an expression of a malaise about human's relationship to nature, and the search for a redefinition? Should not this discomfort be acknowledged in trying to both advance UES and make cities more livable? I would say we are not sure about the role of nature in cities, fundamentally, though we feel nature has an important role.

\section{CITIES AS ANTHROPOGENIC ENVIRONMENTS}

At the risk of redundancy, the city is an anthropogenic creation that dramatically alters the environment as it is built and rebuilt.

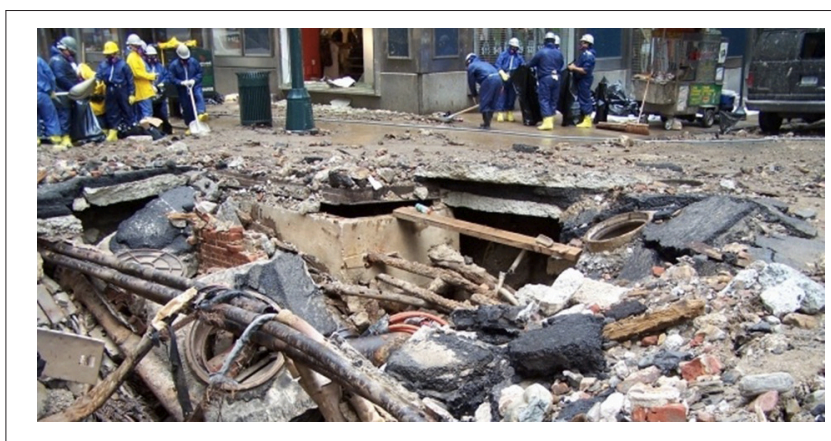

FIGURE 2 | Urban Soils.

While urban ecologists have developed a robust literature on urban soils, trees, stormwater management and other services, studies often seems to float upon an assumption that the environment in which these exist is altered. Questions I would be interested in having investigated include how similar or different is urban soil in different locations within the city to the soil that was once there and how that then affects the plants and insects liable likely to thrive in those locations? Does the altered soil lead to urban homogenization in vegetation as such soil may no longer support indigenous vegetation because most urban soils are fill and compacted (Figure 2)? How well do trees fare under conditions of air pollution, or building-created wind tunnels and shading (Spirn, 1984)? Logic would have it that UES are highly impacted by their urban conditions and may also be temporarily impacted by high air pollution, or climate-a late or early spring, a hot summer. How might this vary by city?

I suggest it would be useful to attempt to classify urban environments in which the UES exist into distinct biomes, just like is done for biotic communities on the planet. That is, UES are contingent on the specific form, history, economy, infrastructure and climate zone of the city, the urban biome ${ }^{1}$.

The UES in cities are almost fully human choices (they needn't be there at all) but humans chose to include them or not eradicate what grows in a feral space. Investigating, understanding how and why the UES that exist city-by-city are chosen is an integral aspect of UES. These choices need to be joined up with the physical constraints (like high air pollution). This is different than the prevailing advocacy approach: measuring the benefits of trees or biofiltration by soils, for example. Such an approach would study UES as a human created and constrained urban element. And the UES would differ by city biome-those in the developed world may have less pollution impacts than, say, Beijing or Dehli.

This would be a novel approach that would recognize cities as human creations that differ depending on where they are situated and number of important social, political and economic factors. Most likely, a less wealthy city would have more feral spaces (think Detroit). A wealthier city (think NYC) could have less of those, but the plant palate of each is constrained by climate, compared to, for example, Los Angeles. In developing cities, the land use may vary enormously, impacting the space for UES.

\footnotetext{
${ }^{1}$ I am thankful to Darrel Jenerette, Meghan Avolio, Diane Pataki, and others for
} inspiring this concept, I take full credit for its particular expression in this paper. 
In contrast, much of the existing literature "naturalizes" UES, as though UES simply exist. The very term, urban forest, for example, shows how this works. A tree plantation is rarely referred to as a forest, it is seen as what it is, a monocrop tree plantation-like an agricultural field. But in cities, when humans select and plant trees from different regions of the globe, that are subjected to compacted soils, arbitrary spacing, human determined watering regimes, pruning and fertilizing, the UE community deems these an urban forest. Rather trees in the city are yet another anthropogenic object that retains "intrinsic" systems and processes but conditioned by environments made by humans. [As an aside, I interviewed park and open space managers in Paris about "the urban forest." The manager looked at me quizzically, saying Paris had forests: they were the Bois de Boulogne and the Bois de Vincennes, but trees in Paris did not a forest make (2004)].

\section{THE ROLE OF SOFT AND HARD INFRASTRUCTURES}

Cities are the result of agglomerations of hard and soft infrastructures. By that I mean the hard infrastructures of pipes, buildings, wires, roads and the soft infrastructures of rules, codes, laws, and conventions. Consider an airport, a hard infrastructure: it cannot function without soft infrastructures of rules about size of runways, distance between planes, passenger loading and unloading conventions and more. Urban nature (the UES) exists in places that are determined by the interplay between hard and soft infrastructures-zoning land for parks, establishing planting strips along streets, zoning single-family areas or requiring open spaces in exchange for development rights. This dynamic interdependence creates the cities we know, as well as lock-in phenomena that makes it difficult and costly to change infrastructure as it means also changing how people do things, the rules, codes, procedures, politics, and funding sources.

If indeed humans choose to manage cities through increasing UES, this will require coupled shifts, the shift in rules and regulations, goals and processes and shifts in urban form, infrastructure and function-socio-technical-ecological changes-driven by human decision-making. Where the MEA and UES fit is not a foregone conclusion as humans will have to determine that fit. Currently, benefits from UES remains contested science (Pataki et al., 2011, 2013 among others), and UE implementation and maintenance issues are substantial (Pincetl et al., 2013; Schwarz et al., 2015), raising questions about their viability in poor cities or less developed cities. Population densities, conflicting urban goals (concentration of housing for transportation efficiencies, versus space for parks, solar DG and other) remain outside of the UES literature, but should not. For, if in the twenty-first century, there are indeed potential benefits of UES, the UES community must be able to engage in these issues of urban morphology, trade-offs, and urban biome specificities.
An urban role for nature needs to be based on an agreement that it is probably important to people, but that what that nature is, remains contentious-and not simple. In the current California mega-drought, many people in Los Angeles have chosen brilliant green astroturf for their lawn replacement rather than native or drought tolerant plants. Clearly astroturf does not host biodiversity, is most likely not very pervious, will add unequivocally to urban heat; it is a symbolic nod to nature, but not a UES.

\section{TOWARD STUDYING URBAN BIOMES}

Certainly the scientific method that has been applies to UES, a transposition of ES into the city, remains important to conduct in order to describe what natural elements of the urban infrastructure do, and how they perform. But as I have tried to express, these environments are not neutral backdrops. They are the product of historical change, a dramatic transformation in the human relationship to the planet. Thus, as a scientific community, we should explore ecology in cities more explicitly as a co-produced unique artifact driven by human choice, full of unintended consequences, and constrained by hard and soft infrastructures that operate in specific ways in specific cities and nations. UES are contingent on the human and urban structure they find themselves in: a new kind of biome. This biome is directly curated by humans. By beginning with the city as the biome, and categorizing cities as suggested above, by location, level of development, type of infrastructure, density and other criteria, we can then look at the UES as emerging from that physical environment, a physical environment that is humanly created.

At the same time, it is clear that the interest in UES, the belief that the services of ecosystem in cities can make cities more livable, is the expression of a human sentiment that "nature" in cities is important today. And if we do believe that nature in cities has an important role in making them more livable, then how do we engage with the society that regulates it? In part, understanding that city and place, will help to figure out how to make UES relevant and operationalized as an infrastructure. If we find that people like astroturf at least as well as lawns, then the challenge for insuring that people have access to urban nature is a difficult one.

\section{ACKNOWLEDGMENTS}

Much of this thinking developed as a result of a National Science Foundation Sustainability Research Network proposal that was not funded. I wish to thank Diane Pataki (Ecology, University of Utah), Joshua Newell (School of Natural Resources, University of Michigan) Terri Hogue (Engineering, Colorado School of Mines), Mikhail Chester (School of Sustainable Engineering, Arizona State University), and Darrel Jenerette (UC Riverside) in particular for fertile intellectual discussions about these issues and their contributions to the proposal, some of which are reflected in this text. 


\section{REFERENCES}

Cosgrove, D. (1993a). The Palladian Landscape: Geographical Change and Its Cultural Representations in Sixteenth Century Italy. University Park, PA: Leicester University Press/Pennsylvanian State, U.P.net.

Cosgrove, D. (1993b). "The picturesque city: natures, nations and the urban since the 18th century," in City and Nature, Changing Relations in Time and Space Humanities Research Center and The Danish Research Council for the Humanities, ed T. M. Kristensen (Odense: Odense University Press), 45-58.

Costanza, R., de Groot, R., Sutton, P., van der Ploeg, S., Anderson, S. J., Kubiszewski, I., et al. (2014). Changes in the global value of ecosystem services. Glob. Env. Change 26, 152-158. doi: 10.1016/j.gloenvcha.2014. 04.002

Creese, W. L. (1996). The Search for Environment, The Garden City Before and After, Vol. 4. Baltimore, MD: Johns Hopkins University Press.

Geddes, P. (1950). Cities in Evolution, Edited by the Outlook Tower Association, Edinburgh and the Association for Planning and Regional Reconstruction. New York, NY: Oxford University Press.

Glacken, C. J. (1967). Traces on the Rhodian Shore: Nature and Culture in Western Thought from Acienct Times to the End of the 18th Century. Berkeley, CA: University of Clifornia Press.

Grimm, N. B., Grove, J. M., Pickett, S. T. A., and Redman, C. L. (2000). Integrated approaches to long-term studies of urban ecological systems. Bioscience 50, 571-584. doi: 10.1641/0006-3568(2000)050[0571:IATLTO]2. $0 . \mathrm{CO} ; 2$

Haase, D., Larondelle, N., Andersson, E., Artmann, M., Borgstöm, S., Breuste, J., et al. (2014). A quanititative review of urban ecosystem service assessments-Concepts, models and implementation. Ambio 43, 413-433. doi: 10.1007/s13280-014-0504-0

Howard, E. (1902). Garden Cities of Tomorrow. London. Reprinted edited with a Preface by Osborn, F. J. and an Introductory Essay by Lewis Mumford. London: Faber and Faber, [1946].

Jackson, J. B. (1994). A Sense of Place, a Sense of Time. New Haven: Yale University Press.

Luccarelli, M. (1995). Lewis Mumford and the Ecological Region, the Politics of Planning. New York, NY: The Guilford Press.

Marx, L. (1964). The Machine in the Garden, Technology and the Pastoral Ideal in America. Oxford: Oxford University Press.

McHarg, I. (1992). Design with Nature. New York, NY: John Wiley \& Sons.

McNeill, J. R. (2001). Something New Under the Sun, an Environmental History of the Twentieth Century World. New York, NY: W.W. Norton \& Company.

Naeem, S., Ingram, J. C., Varga, A., Agardy, T., Barten, P., Bennett, G., et al. (2015). Get the Science Right when Paying for Nature's Services. Science 347, 1206-1207. doi: 10.1126/science.aaa1403

Parsons, K. C., and Schuyler, D. (eds.). (2002). From Garden City to Green City, The Legacy of Ebenezer Howard. Baltimore, MD: Johns Hopkins University Press.

Pataki, D. E., Alberti, M., Cadenasso, M. L., Felson, A. J., McDonnell, M. J., Pincetl, S., et al. (2013). City trees: urban greening needs better data. Nature 502, 624. doi: $10.1038 / 502624 \mathrm{~d}$
Pataki, D. E., Carreiro, M. M., Cherrier, J., Grulke, N. E., Jennings, V., Pincetl, S., et al. (2011). Coupling biogeochemical cycles in urban environments: ecosystem services, green solutions, and misconceptions. Front. Ecol. Env. 9, 27-36. doi: 10.1890/090220

Pickett, S. T. A., Buckley, G. L., Kaushal, S. S., and Williams, Y. (2011). Socialecological science in the humane metropolis. Urb. Ecosyst. 14, 319-339. doi: 10.1007/s11252-011-0166-7

Pincetl, S., Gillespie, T., Pataki, D. E., Saatchi, S., and Saphores, J. D. (2013). Urban tree planting,function or fashion? Los Angeles and urban tree planting campaigns. Geo. J. 78, 475-493. doi: 10.1007/s10708-012-9446-X

Rome, A. (2001). The Bulldozer and the Countryside. New York, NY: Cambridge University Press.

Rosenzweig, R. (1983). Eight Hours for What We Will, Workers and Leisure in an Industrial City, 1970 -1920. Cambridge: Cambridge University Press.

Schwarz, K., Fragkias, M., Boone, C. G., Zhou, W., McHale, M., Grove, M., et al. (2015). Trees grow on money: urban tree canopy cover and environmental justice. PLoS ONE 10:e0122051. doi: 10.1371/journal.pone.0122051

Seller, C. C. (2012). Crabgrass Crucible: Suburban Nature and the Rise of Environmentalism in 21st Century America. Chapel Hill, NC: University of North Carolina Press.

Spirn, A. (1984). The Granite Garden. New York, NY: Basic Books.

Summers, J. K., Smith, L. M., Case, J. L., and Linthurst, R. A. (2012). A review of the elements of human well-being with an emphasis on the contribuiton of ecosystem services. Ambio 41, 327-340. doi: 10.1007/s13280-012-0256-7

Tanner, C. J., Adler, F. R., Grimm, N., Groffman, P. M., Levin, S. A., Munchi-South, J., et al. (2014). Urban ecology, advancing science and society. Front. Ecol. Env. 12, 574-581. doi: 10.1890/140019

Thacker, C. (1983). The Wildness Pleases, the Origins of Romanticism. New York, NY: St. Martin's Press.

Whyte, W. H. (1970). The Last Landscape. Garden City; New York, NY: Anchor Books.

Williams, R. (1973). The Country and the City. New York, NY: Oxford University Press

Williams, R. (1980). Ideas of Nature in Problems in Materialism and Culture, Selected Essays. London: Verso Editions. 67-85.

$\mathrm{Wu}$, J. (2014). Urban ecology and sustainability: the state-of-the-science and future directions. Landsc. Urban Plan. 125, 209-221. doi: 10.1016/j.landurbplan.2014. 01.018

Conflict of Interest Statement: The author declares that the research was conducted in the absence of any commercial or financial relationships that could be construed as a potential conflict of interest.

Copyright (C) 2015 Pincetl. This is an open-access article distributed under the terms of the Creative Commons Attribution License (CC BY). The use, distribution or reproduction in other forums is permitted, provided the original author(s) or licensor are credited and that the original publication in this journal is cited, in accordance with accepted academic practice. No use, distribution or reproduction is permitted which does not comply with these terms. 